Res Pública Revista de Historia de las Ideas Políticas

ISSN: 1131-558X

http://dx.doi.org/10.5209/rpub.64991

\title{
La limitación constitucional del poder: un estudio sobre la asamblea democrática ateniense en la Guerra del Peloponeso
}

\author{
Tomás P. Bethencourt* \\ Recibido: 8 de julio de 2019 / Aceptado: 13 de enero de 2020
}

Resumen. La Guerra del Peloponeso fue un conflicto a gran escala entre la Liga del Peloponeso y la Liga de Delos, la primera liderada por Esparta y la segunda por Atenas. Sus consecuencias sacudieron a todo el mundo griego, aunque el caso de Atenas es particularmente interesante dado que llevó a la revisión de las leyes de Solón y Dracón, estableciendo, como resultado del proceso, barreras legislativas a la asamblea, limitando su poder en lo que podemos considerar como un hito constitucional. El objetivo en este trabajo es el de explicar de dónde nace esta necesidad de barreras legislativas. Ante esto, la hipótesis de trabajo es que nace tanto del cuestionamiento de los principios democráticos, relacionados con la libertad ciudadana, así como de la necesidad de protegerlos.

Palabras clave: constitución; politeia; democracia; isonomía; isegoría.

\section{[en] The Constitutional Limitation of Power: A Study on the Athenian Democratic Assembly during the Peloponnesian War}

\begin{abstract}
The Peloponnesian War was a large scale conflict between the Peloponnesian League and the Delian League, the former being led by Sparta and the latter by Athens. Its consequences shook the Hellenic world, but the case of Athens is particularly interesting, given that it led to the revision of the laws of Solon and Draco with the result of giving legislative bounds to the assembly, limiting its power in what can be considered a constitutional milestone. The goal of this paper is to explain where did this need for legislative bounds came from. My hypothesis is that it arose from both the questioning of democratic principles, related to civic liberty, and the need to safekeeping them.
\end{abstract}

Keywords: constitution; politeia; democracy; isonomia; isegoria.

Sumario. 1. Introducción. 2. La Guerra del Peloponeso: la expedición a Sicilia y la situación posterior de Atenas. 2.1. Tras diez años de guerra. 2.2. La Paz de Nicias y la reanudación de la guerra. 2.3. Alcibíades, Nicias y la expedición a Sicilia. 3. Isonomía, isegoría y demokratía. 3.1. La perspectiva democrática. 3.2. Los críticos de la democracia. 3.3. Libertad y demokratía. 4. La asamblea: crisis constitucional y limitación del poder político. 4.1. La revolución oligárquica del 411 AC y la batalla de Arginusas. 4.2. La revisión de las leyes (410-399 AC). 5. Conclusión.

Cómo citar: P. Bethencourt, T. (2020). La limitación constitucional del poder: un estudio sobre la asamblea democrática ateniense en la Guerra del Peloponeso. Res Pública. Revista de Historia de las Ideas Políticas, 23(1), 1-10.

\section{Introducción}

La Guerra del Peloponeso (431-404 AC) fue un conflicto a gran escala que enfrentó a la Liga de Delos, liderada por Atenas, contra la Liga del Peloponeso, liderada por Esparta, algo menos de tres décadas después de la última guerra médica. Las causas son variadas y la alianza de Atenas y Esparta ya se resentía por episodios como la rebelión del monte Itome (464 AC) en la que Esparta rechazó a los hoplitas atenienses que habían llegado a Lacedemonia después de ser solicitados por la propia
Esparta. Sin embargo, para Tucídides la razón principal subyacente a la alegada por los lacedemonios es "el crecimiento de los atenienses en poder, que atemorizaba a los Lacedemonios y los forzó a la guerra"2.

Este extenso conflicto es dividido por los historiadores en tres fases: en primer lugar, la fase que constituyó la guerra arquidámica hasta el $421 \mathrm{AC}$, año de la firma de la Paz de Nicias; en segundo lugar, la fase en cuyo marco se encuentra la desastrosa expedición ateniense a Sicilia (415 AC) y, finalmente, la guerra de Decelia. En este trabajo me centraré especialmente en la Paz de

\footnotetext{
Universidad de Málaga

tomaspachecob@gmail.com

Tucídides, Historia de la Guerra del Peloponeso, 2a ed., tr. Francisco Romero Cruz, Madrid, Cátedra, 1994, 1.23, p. 67. 
Nicias y en la expedición a Sicilia, con énfasis en el debate previo a la misma y sus consecuencias, debido al papel central que jugó en el desenlace de la guerra y la capitulación de Atenas en el 404 AC.

Este papel fundamental de la empresa ateniense a Sicilia se debe a los cambios políticos que se produjeron a raíz de ella, dadas sus consecuencias demográficas, económicas y sociales. Así, en el 411 AC, el gobierno democrático es reemplazado durante un breve período por una oligarquía: el Consejo de los Cuatrocientos, que no duraría más de un año. Esta traumática experiencia, en una ciudad de arraigada tradición democrática, provoca el inicio de la revisión de los códigos de Solón y Dracón, en el 410 AC, junto con su codificación, esto es, el paso a la ley escrita. Esta fue interrumpida por el gobierno filoespartano impuesto a Atenas tras su rendición en el 404 AC y continuado hasta el 399 AC tras la restauración del gobierno democrático ${ }^{2}$, con la importante consecuencia de una regulación legal de los procesos deliberativos, indisolublemente ligada a la idea de constitución (politeia).

Así pues, mi objetivo será responder a la siguiente pregunta de investigación: ¿qué es lo que inspira la necesidad de una ley escrita que limite o regule el poder de la asamblea democrática? Mi hipótesis es que esta necesidad nace del cuestionamiento de los principios de isonomía (igualdad en virtud de ser ciudadano) e isegoría (igualdad en el acceso al foro público), relacionados con los sentidos de la eleuthería (libertad) con consecuencias como la experiencia de la crisis constitucional del 411 AC, así como de la necesidad de resguardar estos mismos principios. Como se verá, algunas de las acciones de la asamblea durante la guerra llevaron a este periodo de inestabilidad constitucional.

Para ello, se expondrán primero los hechos más relevantes de la expedición, sobre todo lo que concierne al debate previo, y delinearé las consecuencias económicas, demográficas y políticas. Posteriormente, se realizará un análisis de los conceptos de isonomía, isegoría y demokratía, atendiendo a su importancia para la tradición democrática y su relación con el resguardo de las cívicas de los ciudadanos. Después, se explorará la profunda crisis constitucional de Atenas en el $411 \mathrm{AC}$, de manera que se vea con claridad en qué sentido los principios anteriormente expuestos son cuestionados, con la consecuencia de la limitación del poder político de la asamblea mediante un proceso proto-constituyente, que será expuesto. Por último se recapitularán los pasos seguidos en la argumentación y la demostración de la hipótesis.

\section{La Guerra del Peloponeso: la expedición a Sicilia y la situación posterior de Atenas}

Para entender las circunstancias que llevaron a Atenas a emprender la expedición a Sicilia es necesario volver atrás brevemente, a la firma de la Paz de Nicias, de for-

\footnotetext{
M. H. Hansen, The Athenian Democracy in the Age of Demosthenes: Structure, Principles, and Ideology, tr. J.A. Cook, Oxford, Blackwell, 1991, pp. 162-163.
}

ma que pueda verse con claridad el estado tanto de Atenas como de Esparta, y el desgaste de ambas poleis tras una década de combates.

\subsection{Tras diez años de guerra}

Diez años antes de la expedición, en el 425 AC, Atenas conquistó Pilos, una pequeña ciudad situada al norte de la bahía de Navarino, ubicada enfrente de la isla inhabitada de Esfacteria ${ }^{3}$. Una vez que Agis II, sucesor de Arquidamo, escuchó la noticia de la caída de Pilos, comandó a sus tropas de vuelta - pues había invadido el Ática- a Laconia para intentar recuperar la ciudad, pero durante las operaciones un contingente de lacedemonios quedó atrapado en Esfacteria, rodeado por la flota ateniense. Para ellos la situación era desesperada, puesto que no tenían forma de aprovisionarse, ofreciendo incluso emancipar a cualquier ilota que pudiera llevar comida a la isla, lo cual sin duda animó a muchos voluntarios que no fueron disuadidos ni por las muchas ejecuciones sumarias de los atenienses ${ }^{4}$.

Por ello, en un agitado debate en Atenas, el famoso Cleón recriminó a los strategoi su incapacidad para acabar con la resistencia lacedemonia, en la que se contaban ciento veinte espartanos. En ese momento Nicias, uno de los strategoi, espetó a Cleón que él debería tomar el mando si tan mal trabajo hacían los actuales comandantes, ante lo cual Cleón, con limitada experiencia militar, no pudo más que aceptar para mantener intacta su reputación ${ }^{5}$. Pese a ello, el contingente en Esfacteria se rindió, y un gran golpe fue dado a la leyenda espartana y a su moral pues ciento veinte espartanos con fama de luchar hasta la muerte se rindieron en esa ocasión ${ }^{6}$. Esto resultó ser clave, pues los lacedemonios emprendieron la búsqueda de un acuerdo para conseguir el regreso de los prisioneros y un cese de las hostilidades, aunque estas se prolongaron un tiempo más debido a las agresivas políticas de Cleón.

En el 424 AC la guerra tomó un cariz algo más favorable para Esparta, debido a que el exitoso general Brásidas, que destacó por su habilidad diplomática en sus negociaciones con los tesalios y Pérdicas II de Macedonia, logró incitar una serie de rebeliones contra Atenas e infringirles una dura derrota con la rendición de Anfípolis, colonia de esta, con el golpe financiero que esto supuso y el poder de negociación que significaba para el regreso de los prisioneros de Esfacteria y la lograda tregua de un año, en el $423 \mathrm{AC}^{7}$. Debido a ello, numerosas ciudades se rindieron ante Brásidas, e incluso los ciudadanos de Escíone le otorgaron una corona dorada y lo aclamaron "liberador de Grecia".

Estas defecciones al bando peloponesio dificultaron el mantenimiento de la tregua, al menos en relación con estas ciudades. Para el 422 AC, Cleón persuadió a la asamblea para enviar un ejército de unos cuatro mil

\footnotetext{
Tucídides, op. cit., 4.3, pp. 316-317.

V. Parker, A History of Greece: 1300 to 30 BC, Chichester, Wiley Blackwell, 2014, p. 205.

Tucídides, op. cit., 4.27-29, pp. 334-336.

V. Parker, op. cit., p. 205.

Ibidem, p. 207.

Tucídides, op. cit., 4.121, p. 398.
} 
soldados a Calcídica y recuperarlas; la primera que cayó fue Torone, en la isla de Eubea. Luego se dirigió a Anfípolis, donde chocó con las fuerzas de Brásidas y fue derrotado, aunque ambos generales cayeron en la batalla . Esto abrió el camino para las negociaciones de paz entre los agotados contrincantes.

Estas negociaciones duraron todo el invierno del 422 al 421 AC, año en que fue firmado el tratado de paz con Nicias como negociador principal de parte de Atenas y el viejo rey de Esparta vuelto del exilio, Plistoanacte ${ }^{10}$. Durante las negociaciones, Esparta representaba los intereses de la Liga del Peloponeso, pero el revés de la negativa de los ciudadanos de Anfípolis de volver al bando de Atenas y que prevenía el regreso de los prisioneros espartanos de Esfacteria llevó a Esparta a firmar un tratado paralelo, en el que establecía una alianza con Atenas que perjudicó fuertemente la reputación de Esparta ante toda la Liga ${ }^{11}$, incluso con algunas ciudades como Corinto desertando y estableciendo contactos con los argivos, enemigos mortales de los atenienses y conminándoles a entrar en una alianza defensiva ${ }^{12}$. Así quedó firmada la Paz de Nicias.

\subsection{La Paz de Nicias y la reanudación de la guerra}

El recorrido anterior sobre los años previos al tratado de paz es relevante para este trabajo por dos razones: la primera es que pone de relieve que el conflicto continuado había dejado tanto a Atenas como a Esparta una situación económica menos que deseable, además de la incapacidad de lograr una victoria decisiva para ninguno de los bandos. La segunda, y más importante, es que ya nos muestra qué es lo que más adelante sería entendido como un liderazgo errático por parte del gobierno democrático ateniense, culpable -o tenido como tal- de alargar indefinidamente la guerra. Esto especialmente en referencia a la designación de Cleón como strategos para solucionar el problema de Esfacteria a petición de Nicias ${ }^{13}$. Gracias a esto la situación se planteó como un ganar-ganar para los rivales de Cleón, pues si era derrotado se desharían de él y, si ganaba, resolverían el problema de los espartanos de Esfacteria.

Este movimiento en la asamblea, pese a que la situación pudo resolverse haciendo prisioneros a los espartanos, tuvo consecuencias perjudiciales a largo plazo. Cleón era uno de los más fervientes partidarios de la guerra e imposibilitó capitalizar la captura de los soldados de Esfacteria cuando los espartanos estaban ansiosos por recuperar a sus hombres, así como por negociar un acuerdo de paz. La continuación del conflicto conllevó una rápida desmejora del estado financiero de la polis, además de las múltiples rebeliones y batallas resaltadas en el punto anterior.

Podemos pensar en la Paz de Nicias como un tratado que estableció tablas acerca del resultado de la

V. Parker, op. cit., p. 208.

10 D. Kagan, The Peace of Nicias and the Sicilian Expedition, Ithaca, Cornell University Press, 1996, p. 124.

11 Tucídides, op. cit., 5.23-24, pp. 430-431.

$12 \quad$ Ibidem, 5.27, p. 433.

13 Ibidem, 4.27-30, pp. 334-336. guerra o, mejor dicho, un status quo ante bellum del que Atenas había salido mejor parada, puesto que la reputación de Esparta estaba gravemente dañada y Argos amenazaba con abandonar la Liga del Peloponeso. La paz era frágil, y en el 420 AC Esparta negoció una alianza con los beocios, enemigos de Atenas ${ }^{14}$. Por su parte, Atenas negoció una alianza con Argos y sus aliados, Mantinea y Elis, con un joven Alcibíades encabezando las negociaciones. Así, una disputa fronteriza alrededor de un templo a Apolo de Argos con Epidauro, miembro de la Liga del Peloponeso, obligó a Atenas a intervenir de parte de su nuevo aliado ${ }^{15}$. La segunda fase de la guerra empezaba. Para Ronald Legon, Atenas pretendía llenar el vacío de poder dejado por una debilitada Esparta, y precipitó así la reanudación de las hostilidades ${ }^{16}$.

Los atenienses y los espartanos volvieron entonces a encontrarse en la batalla de Mantinea, haciendo los primeros una "liga democrática" con Argos, Elis y Mantinea. La batalla fue de resultado imprevisible y de una escala excepcionalmente grande ${ }^{17}$, saldándose finalmente con una victoria de los peloponesios liderados por el rey Agis II y la masacre de los mantineos. La importancia militar de esta victoria es que, como señala el historiador Donald Kagan, podría haber acabado con la Guerra del Peloponeso pues seguramente Tegea habría sido la siguiente en caer, aislando a Esparta de sus aliados y dificultándole el control de Mesenia ${ }^{18}$. En cambio, el golpe moral para los atenienses fue efectivo y sirvió para recuperar el prestigio perdido con el episodio de Esfacteria. Más aún, produjo "una reacción oligárquica que tras muchas fluctuaciones ganó dominio sobre toda Grecia", como recoge Kagan de Busolt ${ }^{19}$.

\subsection{Alcibíades, Nicias y la expedición a Sicilia}

En Atenas el liderazgo se había dividido entre los moderados, dirigidos por el experimentado Nicias, y los partidarios de políticas agresivas, liderados por Alcibíades. El primero propugnaba lanzar una expedición contra Calcídica y Macedonia para recuperar los territorios perdidos ante Brásidas - postura inicialmente exitosa debido a la cercanía del rey Pérdicas con los espartanos pero que solo culminó en un bloqueo por mar-, mientras que Alcibíades quería continuar con su estrategia en Argos, ahora estancada por la ruptura con Elis y Mantinea. El problema para Atenas era su incapacidad de mantener una política consistente, e Hipérbolo, sucesor de Cleón en su facción en la asamblea, convocó un ostracismo que permitió a los atenienses elegir entre Nicias y Alcibíades. No obstante, Alcibíades propuso a Nicias unirse contra Hipérbolo y con la unión de sus fuerzas adoptaron una exitosa acción política que culminó con el ostra-

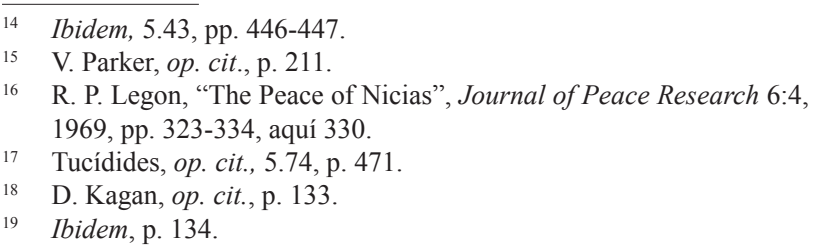


cismo de este último, que sería asesinado en Samos por oligarcas samios en el $411 \mathrm{AC}^{20}$.

Este ostracismo probó su debilidad como mecanismo institucional para la estabilidad constitucional, puesto que podía "confirmar a un líder o una política apoyada por una mayoría clara, pero sin esa mayoría era claramente deficitaria" ${ }^{21}$. Así pues, la división interna no paró de crecer y, cuando se eligieron los nuevos strategoi, Nicias y Alcibíades estaban entre ellos. Además, la paz había permitido que una generación de jóvenes madurase y que nuevas naves se construyesen, necesitando solo experiencia de combate, para lo cual se lanzó la sangrienta campaña contra los melios y que acabó con su masacre, aprobada por la asamblea ${ }^{22}$.

En el invierno del 416-415 AC llegó a Atenas una embajada de la ciudad siciliana aliada, Segesta, y una facción de leontinos que pedía ayuda frente a su vecina, Selinunte -que tenía a Siracusa como protectora- invocando la antigua alianza con Atenas, que los recibió gratamente, pues su petición sería un pretexto excelente para atacar la isla ${ }^{23}$. No obstante, la conveniencia de la invasión es altamente discutible puesto que las consecuencias de una derrota podían ser catastróficas. Para Tucídides la razón para la expedición estaba clara: ambición y conquistar la isla ${ }^{24}$. Las masas, nos dice, ignoraban la magnitud de la invasión y no entendían la oposición que encontrarían ${ }^{25}$.

Como se verá, pese a que alguien podría culpar a la asamblea de dejarse convencer por Alcibíades, puede argumentarse que eso sería un error puesto que Nicias también intentaba hacer lo mismo en igualdad de condiciones, y Alcibíades solo ejerció mejor la oratoria para argumentar su posición. El error de la asamblea en este sentido recae, más bien, en su gestión de las consecuencias.

En una segunda asamblea, en la que se precisarían solo los últimos detalles de la invasión, Nicias volvió a plantear la cuestión de si los barcos debían partir en absoluto, con un argumento que se centraba esta vez en que la expedición no venía en el mejor momento y las posibilidades de éxito no eran las mejores: Atenas apenas se recuperaba tanto de la plaga, como de la guerra y empezaba a reponer sus arcas, sin contar las rebeliones que debían sofocar en Calcídica. Además, aludió ad hominem a Alcibíades y sus partidarios, diciendo que no consideraban más que su propio beneficio y la posibilidad de ejercer el mando durante la conquista.

Alcibíades respondió al ataque, pero buscó una postura conciliadora entre su juventud y la experiencia de Nicias. Para él, el poder de Sicilia no era preocupante y la empresa no acarreaba grandes riesgos ya que la flota de reserva podía defender la polis. Apeló al orgullo y honor ateniense, y a la necesidad de defender a los aliados. Mostrar ahora miedo podía amenazar la seguridad del imperio. Finalmente, añadió fines no tan modestos:

\footnotetext{
D. Kagan, The Fall of the Athenian Empire, Ithaca, Cornell University Press, 1991, p. 146.

si la expedición tiene éxito, como sucedería en su visión, los atenienses podrían controlar toda Grecia, pues su poder se vería reforzado por la adición de Sicilia ${ }^{26}$. Así, concluye Alcibíades que una ciudad que no es pasiva (apragmon) sería rápidamente destruida de comenzar a serlo ${ }^{27}$.

Este apartado ha sido necesario para cumplir al menos dos funciones. La primera es para poder hacer referencia a los hechos que en ella se describen en los siguientes puntos. La segunda es que pone de manifiesto varios de los fallos que serán posteriormente achacados al sistema democrático: el mando de Cleón, el retraso de la paz con Esparta, el ostracismo de Hipérbolo y la expedición a Sicilia. Para diversos autores, esto se debe a que los funcionamientos de la democracia facilitan el mando de la masa y el advenimiento de líderes populares o demagogoi. En el siguiente apartado se explica hasta qué punto esto es así, y se esbozará por qué la asamblea decidió limitar sus propias capacidades.

\section{Isonomía, isegoría y demokratía}

En este apartado se analizarán, siguiendo a Aristóteles, los principios que se encuentran en la base del sistema democrático ateniense, estos son: isonomía, isegoría e isokratía. Luego, se explicará la relación que existe con la defensa de las libertades ciudadanas y, finalmente, se argumentará en qué sentido son cuestionados en los años finales del conflicto. Como se verá, estos conceptos son interpretados de forma diferente tanto por los partidarios de la democracia como por sus críticos. Es el cuestionamiento de estos principios por parte de los demócratas lo que precipita la crisis constitucional del $411 \mathrm{AC}$, y la consecuente revisión de la constitución (politeia) de los atenienses.

\subsection{La perspectiva democrática}

Algunas fuentes, como Heródoto en el Debate Constitucional, denotan que isonomía precedió a demokratía como el nombre común dado al gobierno popular o gobierno de las masas, en contraposición a la tiranía y la oligarquía $^{28}$. Está retratada en un sentido eminentemente positivo, con rasgos característicos como la elección por sorteo, auditorías de oficiales públicos y el poder de la asamblea para discutir y decidir todas las cuestiones relacionadas con políticas públicas ${ }^{29}$. Quizá sería posible situar un uso temprano de demokratía en Las Suplicantes de Esquilo, donde hace referencia al pueblo que gobierna la ciudad, o a la mano regidora del pueblo, lo que demostraría una comprensión de Esquilo de la idea detrás del concepto aunque, según Gregory Vlastos, una cosa es tener una frase para una idea y otra es tener una palabra que la engloba ${ }^{30}$.

\footnotetext{
26 D. Kagan, The Peace of Nicias and the Sicilian Expedition, op. cit., pp. 170-185.

Tucídides, op. cit., 6.18, pp. 505-506.

28 G. Vlastos, "Isonomia", The American Journal of Philology 74:4, pp. 337-366, aquí 337.

29 Ibidem.

$30 \quad$ Ibidem, p. 339.
} 
De esta forma, la palabra isónomo/a aparece en dos textos, La canción de Harmodio y Aristogitón y Alcmeón, con un significado político más implícito que el de Heródoto. Para Vlastos, el sentido en el que se emplea la palabra "isónoma" en dicha canción es para celebrar las reformas de Clístenes, y esta -típica de taberna- enaltecía los tiranicidios con una clara intención política. No es coincidencia que se convirtiera en una canción habitual de los partidarios más radicales de la democracia, así como "el eslogan de la democracia igualitaria fundada por Clístenes y fuera llevada a su máxima expresión durante el siglo V"31. Pero, ¿cuál es el significado de isonomía?

Isonomía tiene que ver con igualdad, que a su vez es un concepto o ideal puramente político. Si hacemos una distinción que los atenienses ya conocían bien entre un sentido natural y un sentido normativo de entender esta igualdad, veremos que los demócratas priorizaban el hecho de que todos los ciudadanos "tuviesen iguales derechos en pos de tener igualdad de oportunidades" ${ }^{\prime 2}$. Naturalmente, hablar de derechos en el siglo $\mathrm{V}$ es usar un lenguaje conceptual que no es conocido en el mundo clásico $^{33}$, pero esto solo significa que nuestro lenguaje sobre los derechos representaría solo una manera en la que la libertad ciudadana es protegida en una ciudad $\mathrm{dada}^{34}$. El que los atenienses no manejasen el lenguaje de los derechos no implica que no entendiesen ni buscasen salvaguardar la libertad del individuo. Como se verá más adelante cuando vuelva sobre esta cuestión, parte de esa salvaguarda significa vivir bajo una demokratía, que implica isonomía.

Así la idea de "un hombre, un voto", que aparece en Las Suplicantes de Eurípides supone un tipo de igualdad natural ${ }^{35}$, o la idea de que todos los ciudadanos atenienses tenían el valor suficiente como para participar en la toma de decisiones de la ciudad. Aun así, contrario al planteamiento de Vlastos, Mogens Herman Hansen considera que para ser considerado como un pilar de la democracia, el concepto de isonomía aparece más bien poco: de los oradores atenienses, solo Isócrates la usa, y lo hace peyorativamente en referencia a un ideal democrático desviado, defendido por radicales. Luego, en función de los nombres dados a las naves de guerra es posible saber los valores políticos de una ciudad y, mientras que hay un buen número de trirremes llamadas "Demokratía", no hay ninguna llamada "Isonomía".

Por último, los cultos políticos atenienses incluían tanto a Demokratía y Eleuthería como diosas separadas e independientes, mas no a Isonomía ${ }^{36}$. Así pues, se confunden los usos dados a demokratía e isonomía, pero en pos de la claridad deberíamos entender que ambos se coimplican. En definitiva, isonomía prometía hasta al ciudadano más pobre un igual papel en la legislación,

Ibidem, p. 344

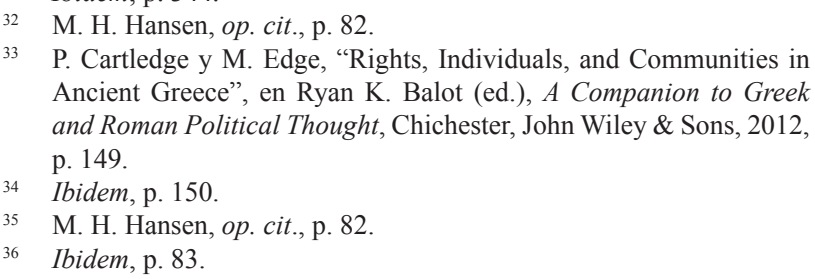

administración y en el poder de la ciudad de hacer cumplir la ley ${ }^{37}$.

Isegoría, por otro lado, era el principio más valorado por los demócratas para Hansen, pues, en sus palabras: "isegoría tiene que ver con la igualdad de oportunidades". Esto es debido a que en una asamblea a la que asistían unos seis mil ciudadanos no es esperable ni razonable que todos intervengan: se trata, pues, de una facultad para aquellos interesados en ejercer sus facultades políticas, para lo que todos tenían oportunidad, "una oportunidad de demostrar excelencia". Para los atenienses, la iniciativa política era estimulada por la ambición y la competencia (philotimia y hamilla) donde la única igualdad relevante es la de partida ${ }^{38}$.

De esta forma, con la igualdad de todos los ciudadanos y la capacidad para intervenir en el debate público en igualdad de condiciones, se genera un régimen isocrático, o gobierno de los iguales, donde todos los ciudadanos poseen los mismos poderes políticos. Esto significa que la igualdad ante la ley, de participación y de poder tienen características esenciales para la democracia y se necesitan entre sí hasta el punto de que una de ellas puede implicarlas a todas ${ }^{39}$. Es decir, todos estos conceptos están en constante y recíproca relación con el otro, y hacen la constitución (politeia) la comunidad política reflejadas en las instituciones de la polis.

\subsection{Los críticos de la democracia}

En cuanto a los detractores del sistema democrático, parece que su discrepancia fundamental recae tanto en la interpretación como en la priorización de un concepto sobre otro, especialmente en referencia a la isonomía, en torno a la cual se articula la crítica a la democracia. Así, a los demócratas les es imputada una noción descriptiva de igualdad, y esto es apreciable en el libro V de la Política de Aristóteles, en el que dice que "la democracia nació de la idea de que aquellos que son iguales en cualquier respecto, también lo son absolutamente" 40 . Dice Hansen: "todos son igualmente libres, por lo tanto alegan serlo absolutamente" ${ }^{41}$. Lo mismo en lo referente a la participación política, como habíamos visto antes, "un hombre, un voto"; todos los ciudadanos son igualmente valiosos como para participar en las decisiones de la asamblea.

Me centraré aquí en la visión de Aristóteles, pues parte de su crítica se dirige a la asamblea de Atenas en el siglo $\mathrm{V}$ y al tipo de democracia que esta representaría. Para él, la democracia es ese gobierno en el que los libres gobiernan ${ }^{42}$. Pero, ¿a qué se refiere con los libres? En sus palabras:

Un principio de la libertad es el de gobernar y ser gobernado a su vez, y ciertamente la justicia democrática es la aplicación de la igualdad en sentido numérico y no proporcionado; de donde se sigue que la mayoría debe

\footnotetext{
G. Vlastos, op. cit., p. 355.

M. H. Hansen, op. cit., p. 84.

G. Vlastos, op. cit., p. 356.

40 Aristóteles, Política, tr. Carlos García Gual y Aurelio Pérez Jiménez, Madrid, Editora Nacional, 1981, V, 1, 1301a1, p. 209.

41 M. H. Hansen, op. cit., p. 82.

42 Aristóteles, op. cit., IV, 4, 1290b1, pp. 175-178.
} 
ser suprema, y que lo que sea que esta pruebe debe ser el fin y lo justo [...] en una democracia, los pobres tienen más poder que los ricos ${ }^{43}$ porque hay más de ellos ${ }^{44}$.

Hace referencia a otro principio de la libertad democrática, aludiendo a los ilotes o ciudadanos privados, que pueden vivir como quieran, pues esa es la marca del hombre libre. Solo este puede ser gobernado y, a su vez, gobernar. Continúa con la descripción del sistema democrático: la elección por sorteo independientemente de las capacidades, el pago por magistratura y participación en las diversas instituciones y, muy especialmente, la idea de que la asamblea - a la que acude esa mayoría de pobres-debe reinar suprema sobre cualquier otra institución ${ }^{45}$. Aunque la discusión continúa, parece que todo el análisis sobre la democracia está edificado sobre la presunción de que son los pobres los que gobiernan, aun cuando el estatus de ciudadano incluye tanto a pobres como a libres ${ }^{46}$. Pero Aristóteles se está refiriendo a un tipo específico de democracia que veremos a continuación, a un régimen despótico que -antes que por demokratía - es traducido muchas veces por demagogia ${ }^{47}$. No se está refiriendo a una politeia.

Esta descripción de la democracia parecería aludir, sobre todo en lo que se refiere al poder de la asamblea, a la quinta forma de democracia que describe Aristóteles en el libro IV, cuando es la masa y no la ley la que gobierna mediante decretos aprobados por mayorías cuyas decisiones acarrean todo el peso legislativo. Este estado de cosas es en el que aparecerían los demagogos ${ }^{48}$.

Aristóteles, sabemos, está pensando en la Atenas del siglo $\mathrm{V}$ y en su crisis democrática. Más en concreto en los paradigmáticos ejemplos de Cleón y Alcibíades. El primero, por convencer a la asamblea (donde gobernarían las masas) de pasar por las armas a todos los hombres de Mitilene, además de vender a las mujeres y niños como esclavos, y pese a que la asamblea recapacitó, este tipo de masacres se verían conforme avanzaba el conflicto, como en Melos.

Además, convenció a la asamblea de rechazar la paz que ofrecía Esparta después de Esfacteria, prolongando el conflicto y propiciando pérdidas tanto económicas como territoriales ante Brásidas. Alcibíades, por su parte, habría convencido a los atenienses de emprender la desastrosa empresa a Sicilia apelando a su vanidad y ambición.

El argumento, parecería, es que los principios que rigen este tipo de democracia son el caldo de cultivo para la aparición de este tipo de líderes. No obstante, hay que señalar que, al menos desde el punto de vista de los demócratas, hablar de demagogo en sentido peyorativo no tiene sentido y el término es disputado, puesto que antes de su conceptualización en Platón y Aristóteles, aparece

\footnotetext{
Énfasis añadido.

Aristóteles, op. cit., VI, 2, 1317b1, p. 257

Ibidem, 1318a1, p. 258.

46 R. Mulgan, "Aristotle's Analysis of Oligarchy and Democracy", en Fred Miller y David Keyt (eds.), A Companion to Aristotle's Politics, Oxford, Blackwell, 1991, p. 316.

47 J. Álvarez Yágüez, "La categoría de política. Aclaraciones desde la perspectiva de un clásico republicano", Isegoría 39, 2008, pp. 31133, aquí p. 328.

48 Aristóteles, op. cit., IV, 4, 1292a1, p. 177.
}

de forma neutral ${ }^{49}$. Y es que, en un sistema en el que, en virtud de la ciudadanía, todo el cuerpo político tenía la posibilidad de participar pero, en la práctica, solo unos pocos lo hacían, lo natural era que estos líderes del pueblo surgieran y que, en un contexto que animaba al debate y la deliberación, desplegaran su capacidad retórica tanto para convencer como para ganar prestigio y poder. No se presenta como algo tan diferente el discurso de Alcibíades a cuando Pericles dijo que los atenienses eran los amos del mar, y gobernarían tanto de él como deseen, en respuesta a los apragmones, llamó Pericles a los defensores de políticas pasivas y como Alcibíades llamó a Nicias en la asamblea ${ }^{50}$.

\subsection{Libertad y demokratía}

Así pues, la libertad o eleuthería era el ideal democrático fundamental y, según el planteamiento de Aristóteles, tenía dos aspectos: poder participar en las instituciones políticas y vivir como uno quisiera. Este último ha estado en el centro del debate entre los historiadores y los filósofos para dirimir la relación que existe entre el mismo y la idea moderna de libertad individual, si es que existe, aunque para Hansen todo el énfasis se ha puesto más en las diferencias que en las similitudes ${ }^{51}$.

Lo que se ha planteado es que la diferencia fundamental recae en que eleuthería hacía referencia a no ser un esclavo, y eso es lo que significaba ser eleutheros. Así pues, eleuthería como "vivir como uno quiera" está ligada a la contraposición libre-esclavo, pero Hansen distingue tres capas conceptuales en eleuthería que varían según tres contextos distintos en las fuentes: social, político y constitucional. El social es la contraposición antes mencionada, por lo que me centraré en los otros dos, siendo el último especialmente relevante para el argumento que quiero plantear. En el segundo sentido se refiere a ser autónomo, no ser dominado por otros, valorado en cualquier sistema político. El ejemplo claro es la unión de las ciudades griegas frente a Persia, con una clara mayoría de oligarquías: "Eleutheria in the sense of autonomia was the freedom of the polis, which is different from freedom within the polis" 52 . En sentido constitucional, tiene que ver tanto con la participación pública como con la libertad personal en la esfera privada. A diferencia de los anteriores, este sentido es eminentemente democrático, pues no se aplica a oligarquías o monarquías. Además, también se aplicaba a los metecos y en ocasiones a los esclavos, no solo a los ciudadanos ${ }^{53}$.

Hay varias razones más para pensar en una noción de libertad ciudadana en un sentido reconocible por nosotros. Si en el pensamiento moderno la libertad trata de la protección de los derechos individuales frente a

\footnotetext{
49 M. Lane, "The Origins of the Statesman-Demagogue Distinction in and after Ancient Athens", Journal of the History of Ideas 73:2, 2012, pp. 179-200, aquí p. 180.

50 D. Kagan, The Peace of Nicias and the Sicilian Expedition, op. cit., p. 184.

51 M. H. Hansen, op. cit., p. 75.

$52 \quad$ Ibidem, p. 74.

53 Ibidem, p. 76.
} 
otros y frente al estado, el caso ateniense no es diametralmente distinto pero referido a la ciudad. Oradores como Lisias o Isócrates declaran que ningún ciudadano puede ser ejecutado sin un proceso legal correspondiente (medena akriton apokteinai, o ninguna ejecución sin juicio). También la tortura a los ciudadanos atenienses estaba prohibida, y había ciertas garantías respecto de la protección del hogar del individuo. Por último, más que la "protección de la persona, de su hogar y de su propiedad, el tesoro más preciado era la libertad de expresión, a menudo suprimida por los partidarios de regímenes autoritarios" $" 54$.

Así, podríamos entender que los atenienses tenían una noción de libertad negativa, para usar la expresión de Isaiah Berlin, si bien de una manera aproximada, relacionada con vivir como ciudadano en una comunidad autosuficiente, libre de la voluntad de un tirano o monarca. Solo puede ser libre quien vive como ciudadano isónomo en un sistema democrático participativo en el que nadie más que el individuo puede hacer leyes que dicten su destino ${ }^{55}$. Vivir en una tiranía, una oligarquía o bajo el domino de otra polis da al individuo inmediatamente una condición de esclavo (douleia) puesto que por definición esto es vivir bajo el control de otros, contraviniendo todos los sentidos de la eleuthería, esto es, revocando al individuo su libertad. Evitar esa condición entonces solo es posible viviendo en una demokratía. En otras palabras, la democracia tendría un sentido negativo en cuanto a que protege la libertad de los ciudadanos de los tiranos y oligarcas ${ }^{56}$.

Así pues, si debe estar presente un régimen democrático que tenga como base los principios de isonomía, isegoría y demokratía para poder salvaguardar las libertades ciudadanas entendidas en el sentido anterior, entonces lo que sucede en el 411 AC es que los ciudadanos son privados de eleuthería y sometidos, de cierta forma, a la esclavitud, constituyendo esto una traumática experiencia. Ello, sumado a las razones para este cambio de régimen, entre las que se encuentra el ya mencionado deficitario liderazgo de la asamblea durante la guerra, es lo que lleva finalmente a poner límites al poder de la asamblea, a reformar la politeia.

\section{La asamblea: crisis constitucional y limitación del poder político}

En este último apartado se expondrá cómo, con el cuestionamiento del sistema democrático y de los principios que lo rigen, se abre una ventana de oportunidad para los partidarios de la oligarquía, que culmina con el derrocamiento de la democracia en el $411 \mathrm{AC}$, aunque no duraría más de un año. No obstante, este régimen sumado al liderazgo democrático previo y a la sangrienta tiranía de los Treinta, compelen a Atenas a un período de reforma constitucional que puede entenderse como un hito en la historia del constitucionalismo.

\footnotetext{
$54 \quad$ Ibidem, p. 77.

55 P. Cartledge y M. Edge, op. cit., p. 151.

56 Ibidem, pp. 151-152.
}

\subsection{La revolución oligárquica del 411 AC y la batalla de Arginusas}

El resultado de la expedición ateniense a Sicilia significó un golpe moral casi definitivo para los ciudadanos de Atenas. Para los campesinos y habitantes urbanos fue una catástrofe, especialmente por la pérdida de mano de obra y la interrupción del comercio, lo que llevo a "variar y radicalizar las posiciones ideológicas con respecto a la democracia" ${ }^{\circ 7}$. Al menos doscientos dieciséis trirremes, de entre los cuales ciento sesenta eran atenienses, se habían perdido, y no había capital en el tesoro para reparar las cien naves que habían podido atracar en el Pireo o para contratar a más tripulantes. También era improbable poder ingresar algo de los aliados, pues el estado de la ciudad inspiraba rebeliones. Sumado a la "escasez de hombres, barcos y dinero", estaba la escasez de liderazgo: Demóstenes, Lámaco, Nicias, y Eurymedon estaban muertos y Alcibíades exiliado ${ }^{58}$.

Esta ausencia de liderazgo fuerte dividió a los atenienses, que vieron como el vacío de poder era llenado por los grupos aristocráticos, enemigos de la democracia (hetairiai). Los que pertenecían a ellos tenían especialmente razones de tipo económico, puesto que la carga de financiar la guerra recaía en ellos especialmente. Paralelamente, el ciudadano medio también tenía que pagar tasas más altas al tesoro público, que se reducía más y más fruto de las múltiples rebeliones y la interrupción del comercio. Respecto de la población, de los veinticinco mil ciudadanos que había para el $431 \mathrm{AC}$, el número se redujo a unos nueve mil después de Sicilia, luego de la cual todos estos problemas llegaron a su punto cumbre.

De esta forma, una facción oligárquica dirigida por Frínico y Pisandro logró hacerse con el poder e instaurar el Consejo de los Cuatrocientos ${ }^{59}$. Para ello, conminaron a la asamblea a derogar la ley del graphe paranomon que podía invocarse para acusar a una propuesta considerada contraria a la ley, lo cual se hizo ${ }^{60}$. Así se instauró el nuevo gobierno oligárquico. Algunos meses después la asamblea volvió a instaurar el graphe paranomon, la democracia fue restaurada y Frínico fue asesinado. Vemos, además, que la capacidad irrestricta de la asamblea para derogar leyes es otra de las causas del éxito de la revolución oligárquica y de la consecuente pérdida de eleuthería. Al año siguiente, en el 410 AC, tiene comienzo el proceso de la revisión de las leyes, en el que me centraré en el siguiente subapartado.

Cuatro años después, en el 406 AC, y dos años antes de la capitulación de Atenas, la asamblea tiene otra desafortunada actuación concerniente a la inesperada victoria en Arginusas, en cuyos detalles no entraré. La guerra en el Egeo no continuaba de forma favorable y Persia se había aliado con Esparta, que ahora comandaba una

J. Roche Cárcel, "La frágil construcción de la democracia en la Grecia Antigua y la búsqueda del orden en la teoría democrática moderna y contemporánea", Res Publica: Revista de Historia de las Ideas Politicas 30, 2015, pp. 15-58, aquí p. 34.

58 D. Kagan, The Fall of the Athenian Empire, op. cit., p. 4.

59 Ibidem, p. 112.

60 J. D. Lewis, "Constitution and Fundamental Law: The Lesson of Classical Athens", Social Philosophy and Policy 28:1, 2011, pp. 2549, aquí p. 32. 
poderosa flota. En Lesbos una flota ateniense que dirigía Conón estaba bloqueada por la del lacedemonio Calicrátidas. En su desesperación, la asamblea designó diez generales y envió una flota con los barcos que quedaban.

Sorprendentemente la batalla se saldó con una victoria, pero el fallo de los strategoi para recoger a los marineros muertos y naufragados debido a una tormenta despertó un revuelo popular que acabó con la ejecución sumaria de seis de los diez generales ${ }^{61}$. John David Lewis señala hasta tres violaciones de las costumbres legales de los atenienses: su juicio fue ante la asamblea y no ante jueces particulares; fueron juzgados juntos y no por separado como correspondía y les fue negada la posibilidad de defenderse ${ }^{62}$. Como vemos, este acto viola también algunas de las libertades señaladas en el apartado anterior como virtudes de la democracia. La reforma era necesaria, pues la guerra había llevado a la asamblea a convertirse en el organismo de tiranía colectiva que criticaba Aristóteles ${ }^{63}$.

\subsection{La revisión de las leyes (410-399 AC)}

Este proceso empieza el año en el que se reestablece el sistema democrático en Atenas, en el 410 AC, y solo se ve interrumpido por el breve y sangriento régimen de los Treinta Tiranos, impuesto por Esparta después de la rendición de Atenas en el 404 AC. Así, en el siglo V, la asamblea tenía poder irrestricto para derogar o aprobar leyes, pero decidió limitar este poder para dar una muy necesitada estabilidad constitucional. De esta manera, como se detallará a continuación, se establece una distinción entre dos tipos distintos de actos legislativos: los decretos y las leyes ${ }^{64}$. Veamos en qué consistieron exactamente estas reformas y cómo limitaban las capacidades de la asamblea.

Es razonable afirmar que el organismo más importante de Atenas era la asamblea (ekklesía) en la que podían participar todos los ciudadanos independientemente de su renta (para el siglo $\mathrm{V}$ ), lo que suponía un número de unos cuarenta mil, de los cuales seis mil hacían aforo para la asamblea, que concentraba el poder legislativo.

Pese a que hay muchos otros organismos, como los árbitros (públicos y privados) o los tribunales, esbozaré brevemente la Boulé o Consejo de los Quinientos y el Areópago. La primera, después de las reformas de Pericles, permitía a los ciudadanos servir por hasta dos años, y la elección se realizaba por sorteo: por cada una de las diez nuevas tribus eran elegidos cincuenta. Sus facultades eran limitadas y fueron adquiriendo competencias, pero valga decir que recogían propuestas de leyes de los ciudadanos y establecían el orden del día para la asamblea, además de revisar que los decretos aprobados en esta no contraviniesen las leyes fundamentales de la ciudad. Por otro lado, el Areópago era un tribunal que se

\footnotetext{
61 D. Paiaro, "Defendiendo la libertad del «dêmos». Control popular y liderazgo político en la democracia ateniense", Anales de historia antigua, medieval y moderna 44, 2012, pp. 33-62, aquí p. 56.

62 J. D. Lewis, op. cit., p. 33.

63 Aristóteles, op. cit., IV, 4, 1292a1, p. 177.

64 R. T. Long. "The Athenian Constitution: Government by Jury and Referendum", Formulations 4:1, 1996, pp. 1-32, aquí p. 7, accesible en línea en http://www.freenation.org/a/f4111.html.
}

reunía en las colinas de Ares. Estaba formado por magistrados retirados cuyo nombramiento era de por vida. Sus decisiones eran altamente respetadas, pues la experiencia de sus miembros les dotaba de cierta mística ${ }^{65}$. Como veremos, con las nuevas reformas hay que añadir a estos organismos las cortes legislativas.

Así pues, la lucha constitucional entre los demócratas y los oligarcas había hecho mella, puesto que ambos buscaban legitimar la "constitución antigua", las leyes de Dracón y Solón. La disputa giraba alrededor de si estos habían sido pioneros de la democracia o de la oligarquía. Además, nadie sabía qué ley era la que estaba vigente, puesto que en doscientos años aún no había sido codificada. Así que esta fue una de las primeras decisiones: establecer una "junta de codificación", que debía recoger todas las leyes vigentes. Rápidamente pudieron proclamar la ley de Dracón sobre el homicidio, y también aquellas acerca de los poderes del Consejo. Pero las de Solón fueron más complicadas, pues tardaron seis años en completarse e inscribirse en el stoa basileios, en el Ágora, de donde fueron removidas en el 404 AC con el gobierno de los Treinta. Hansen recoge que el líder de la junta, un hombre llamado Nicómaco, fue juzgado en el 399-8 por manipular las leyes y ayudar a los oligarcas en el $404 \mathrm{AC}$, pero parece que la acusación no rindió frutos, pues él mismo terminó su tarea ${ }^{66}$.

Una vez restaurada la democracia en el $403 \mathrm{AC}$, el funcionamiento institucional de la misma sería otro ${ }^{67}$. Se decidió que las leyes de Solón y Dracón estarían vigentes hasta nuevo aviso, pero debían ser "revisadas de nuevo, ratificadas y republicadas". Así, se establecieron dos juntas legislativas (nomothetai), elegidas por los Quinientos y la otra por el demos. La primera recibió la tarea de recolectar y publicar de forma preliminar las leyes consideradas, mientras que la segunda tenía que hacer una prueba (dokimasia) a todas las leyes, esto es, después de una audiencia debía votar si una ley debía ser aceptada o no en el código revisado. Luego serían inscritas nuevamente en el stoa basileios con la tarea encomendada al Areópago de velar por la administración de las leyes por parte de los magistrados ${ }^{68}$. Es importante destacar que la asamblea no participó de ninguna forma en este proceso, aunque tuviese capacidad legislativa: la tarea era de los nomothetai, los legisladores. Además, el código revisado incluía un conjunto de leyes constitucionales acerca de los poderes de los órganos de la ciudad. A partir de ese punto, la ley en Atenas era la ratificada por los nomothetai $^{69}$.

Aparece entonces una nueva definición de ley para los atenienses, un nuevo órgano legislativo y un nuevo procedimiento legal para el escrutinio de las leyes, que se distinguían tajantemente de los decretos, y eran elaboradas por los nomothetai (las juntas legislativas) y no por la asamblea. Su aprobación dependía ahora de un proceso similar al de un juicio, "y

\footnotetext{
Ibidem, p. 12 .

M. H. Hansen, op. cit., p. 163.

J. Gállego, "La liberación del dêmos, la memoria silenciada. Atenas, de la violencia oligárquica a la amnistía democrática”, Anales de historia antigua, medieval y moderna 44, 2012, pp. 11-31 aquí p. 30. 68 M. H. Hansen, op. cit., p. 163.

69 Ibidem, p. 164.
} 
si se cuestionaba su validez eran entonces escrutadas por la Corte Popular en un nuevo procedimiento por haber propuesto y ejecutado una ley defectuosa"70. De forma tal que el procedimiento anterior, el graphe paranomon, solo era utilizado frente a decretos, y debía ser entendido como "el enjuiciamiento público por la propuesta inconstitucional de un decreto"71. Vemos, pues, cómo el poder de la asamblea, su capacidad legislativa, queda considerablemente reducido y sometido a procesos legislativos. Mediante estos, episodios como el del 411 AC o la ejecución sumaria de los strategoi de Arginusas no se repetirían fácilmente (con la asamblea derogando la ley del graphe paranomon). Si la asamblea quería derogar una ley, debía convocar a las cortes legislativas ${ }^{72}$.

\section{Conclusión}

Este trabajo ha comenzado con una pregunta de partida ¿qué es lo que inspira la necesidad de una ley escrita que limite o regule el poder de la asamblea democrática? En respuesta a ella, he propuesto como hipótesis de trabajo que esta necesidad nace del cuestionamiento de los principios de isonomía e isegoría, relacionados con los sentidos de la eleuthería, y de sus consecuencias: de las experiencias del 411 AC y del 404 AC, así como de algunas de las acciones de la asamblea durante la guerra.

Para demostrar la hipótesis se empezó con una contextualización histórica de la segunda mitad de la Guerra del Peloponeso, de manera que se pudiesen ver las circunstancias que rodearon este período de reforma y que, incluso, precipitaron las mismas. Además, esto ha permitido mostrar algunas facetas del errático liderazgo de la asamblea durante la guerra, como el inesperado mando de Cleón en Esfacteria, así como la prolongación del conflicto que causó en Atenas una crisis económica y social o la expedición a Sicilia, ejemplo considerado como paradigmático de una de las peores decisiones militares de la democracia.
Tras esto, el trabajo ha analizado los conceptos de isonomía e isegoría como pilares fundamentales de la democracia y he explicado cuál era la relación que tenían con demokratía, y cómo se articulaban como vértebras del sistema político de Atenas. Esto, desde la perspectiva tanto de los demócratas como de los detractores de la democracia, representados aquí por Aristóteles, pero específicamente al tipo de democracia que podemos asociar con la de la Atenas de finales del siglo $\mathrm{V}$, lo que nos ha permitido ampliar la perspectiva para analizar algunos de los errores de la asamblea democrática que acabarían por llevar a ese proceso de revisión legal, pero sin perder la visión de lo que los demócratas entendían por demokratía.

Después, ha presentado cómo podríamos entender el concepto de libertades ciudadanas en Atenas y de qué forma solo pueden ser protegidas por el sistema democrático y la vigencia de sus principios, pues lo contrario haría un esclavo del ciudadano. De esta forma se ha mostrado por qué proteger la vigencia del sistema democrático era vital para salvaguardar la libertad de sus ciudadanos y, para ello, la reforma era necesaria, como prueba la votación de la asamblea para suprimir las instituciones democráticas en el 411 AC.

Finalmente, ha analizado este momento de crisis constitucional, tanto sus causas como sus consecuencias, para ver luego otro error de la asamblea al ejecutar a seis de los strategoi victoriosos en Arginusas, rompiendo en el camino al menos tres de los principios legales de Atenas. Todo ello ha llevado finalmente al análisis del periodo denominado por Hansen como "la revisión de las leyes", y a la demostración de la hipótesis: lo que dio lugar a ese proceso fue tanto el cuestionamiento de los principios de isonomía e isegoría, esto es, del sistema democrático en sí después del liderazgo democrático en la guerra que tuvo como consecuencia el gobierno oligárquico en el 411 AC, como la necesidad de proteger estos mismos principios y la libertad de los atenienses después de una de las mayores crisis constitucionales de su historia.

\section{Bibliografía}

\section{Fuentes}

Aristóteles, Política, García Gual, C. y Pérez Jiménez, A. (tr.), Madrid, Nacional, 1981.

Tucídides, Historia de la Guerra del Peloponeso (2ª ed), Romero Cruz, F. (tr.), Madrid, Cátedra, 1994.

Contrastadas con:

Aristotle, Politics, Benjamin, J. y Carless Davis, H. W. (tr.), Oxford, Clarendon Press, 1920.

Thucydides, History of the Peloponnesian War, Benjamin, J. (tr.), Nueva York, Prometheus Books, 1998.

\section{Referencias}

Álvarez Yágüez, J., "La categoría de política. Aclaraciones desde la perspectiva de un clásico republicano", Isegoría, 39 , 2008, pp. 311-33.

Cartledge, P. y Edge, M., "Rights, Individuals, and Communities in Ancient Greece", en A Companion to Greek and Roman Political Thought, Balot, R. K., (ed.), John Wiley \& Sons, 2012.

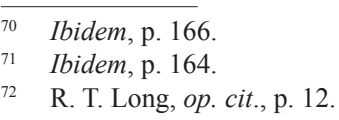


Gállego, J., "La liberación del dêmos, la memoria silenciada. Atenas, de la violencia oligárquica a la amnistía democrática", Anales de historia antigua, medieval y moderna, 44, 2012, pp. 11-31.

Hansen, M. H., The Athenian Democracy in the Age of Demosthenes: Structure, Principles, and Ideology, Cook, J. A. (tr.), Oxford, Blackwell, 1991.

Kagan, D., The Fall of the Athenian Empire, Ithaca, Cornell University Press, 1991.

Kagan, D., The Peace of Nicias and the Sicilian Expedition, Ithaca, Cornell University Press, 1996.

Lane, M., "The Origins of the Statesman-Demagogue Distinction in and after Ancient Athens", Journal of the History of Ideas, 73, 2, 2012, pp. 179-200.

Legon, R. P., "The Peace of Nicias”, Journal of Peace Research, 6, 4, 1969, pp. 323-34.

Lewis, J. D., "Constitution and Fundamental Law: The Lesson of Classical Athens”, Social Philosophy and Policy, 28, 1, 2011, pp. 25-49.

Long, R. T. "The Athenian Constitution: Government by Jury and Referendum", Formulations, 4, 1, accesible en línea en http://www.freenation.org/a/f4111.html, 1996.

Mulgan, R., “Aristotle's Analysis of Oligarchy and Democracy”, en A Companion to Aristotle 's Politics, Miller, F. y Keyt, D. (eds.), Oxford, Blackwell, 1991.

Paiaro, D., "Defendiendo la libertad del «dêmos». Control popular y liderazgo político en la democracia ateniense", Anales de historia antigua, medieval y moderna, 44, 2012, pp. 33-62.

Parker, V., A History of Greece: 1300 to 30 BC, Chichester, Wiley Blackwell, 2014.

Roche Cárcel, J., "La frágil construcción de la democracia en la Grecia Antigua y la búsqueda del orden en la teoría democrática moderna y contemporánea”, Res Publica. Revista de Historia de las Ideas Políticas, 30, 2015, pp. 15-58.

Vlastos, G., "Isonomia”, The American Journal of Philology, 74, 4, 1953, pp. 337-366. 